is of one piece, with a smooth process throughout. The clear implication is that there is no delay in the onset of action, either of the active drug or of the placebo. By using the slope of the graph, one can use all of the trial results, not just those on a particular day. The statistical power is greatly increased and the distinction between drug and placebo enhanced.

Livingston, M. G. \& Clark, A. (1997) Curvaceous model of recovery from depression. Lancet, 349, 447.

Mitchell, A. J. (2006) Two-week delay in onset of action of antidepressants: new evidence. British Journal of Psychiatry, 188, 105-106.

Priest, R. G., Hawley, C. J., Kibel, D., et al (1996)

Recovery from depressive illness does fit an exponential model. Journal of Clinical Psychopharmacology, 16, 420-424.

R. G. Priest Imperial College, University of London, London, UK.

Email: profrgpriest@btinternet.com

doi: 10.I192/bjp.189.5.469a

Author's reply I thank Professor Priest for further insights concerning the difficulty in obtaining sufficient statistical power to distinguish the early drug-placebo response. This is correct but the reason for the difficulty is mainly that the absolute difference between drug and placebo is initially small and when combined with typically low sample sizes the overall power to detect a true difference is insufficient. That said, if the aim of the study is to discover how early an effect is manifest there is no alternative to regular early measures.

Professor Priest then anticipates our next piece of work to which I previously eluded - examination of the trajectories of antidepressant response. He quite cleverly observes that a comparison of the slope of the response curves for the active drug

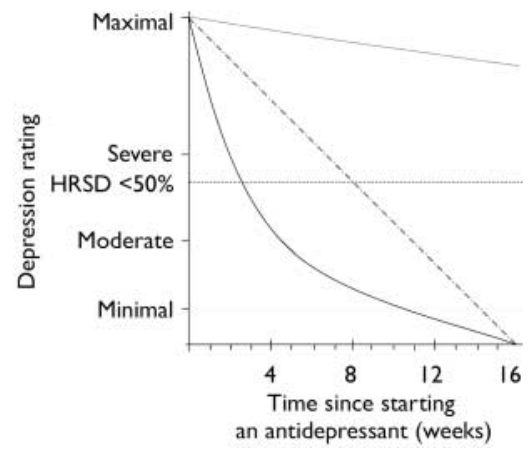

Fig. I Depression rating against time since starting hypothetical antidepressant with rapid $(-)$ and steady ( - . - ) onset. HRSD, Hamilton Rating Scale for Depression; . . . . , placebo response. and placebo is in effect a test of efficacy. It is also suggested that the response is often neither delayed nor steady but actually rapid (or perhaps more accurately 'accelerated'). Allow me to illustrate this point further (Fig. 1). The rate of change of those taking placebo is poor compared with a hypothetical antidepressant with a 'steady' or 'rapid' onset. A delayed onset, as so often suggested, is not illustrated, but I expect readers will be able to sketch their own view of the delayed trajectory. In fact several 'delayed' paths are possible, depending on whether there is a catch-up with the steady path and if so, when.

A. Mitchell Department of Liaison Psychiatry, Leicester General Hospital, Leicester LE5 4PW, UK. Email: alex.mitchel|@|eicspart.nhs.uk doi: 10.1192/bjp.189.5.470

\section{Primary agoraphobia as a specific phobia}

The elegant study of 1920 participants from the Baltimore Epidemiologic Catchment Area programme concluded that 'the implied one-way causal relationship between spontaneous panic attacks and agoraphobia in DSM-IV appears incorrect' (Bienvenu et al, 2006). Bienvenu et al echo the arguments of many researchers, beginning with Marks (1987), that agoraphobia without panic attacks (primary agoraphobia) should be reinstated in DSM-V as a stand-alone diagnosis as in ICD-10.

It has been argued that evolutionary biological reasoning predicts the existence of a 'hard-wired' primary stand-alone agoraphobia, which should be classified with other specific phobias (Bracha, 2006). Specific phobias have been considered as conserved traits that enhanced survival during the human era of evolutionary adaptedness (Nesse, 1999; Bracha, 2006). Primary agoraphobia may similarly be traced back to the fact that humans relied on arboreality as a major escape response long after they diverged from chimpanzees. Homo sapiens expanded beyond its densely forested East-African indigenous niche into sparsely wooded habitats (savannahs and water-front dunes) only about 70000 years ago. In sparsely wooded habitats, anxiety in wide-open spaces was arguably a survivalenhancing trait since opportunities for arboreal escape from large predators were limited (Bracha, 2006). These arguments may be relevant to psychiatric classification and contribute to the 'neuroscience research agenda to guide development of a pathophysiologically based classification system' emphasised in the research agenda for DSM-V (Kupfer et al, 2002).

If, as one of us (Bracha, 2006) has argued, the two types of agoraphobia have different modes of acquisition, there might be some clinical implications. Primary agoraphobia might, like other specific phobias, be especially amenable to virtual reality exposure treatment. In contrast, agoraphobia secondary to panic attacks can be classified in DSM-V and treated along with post-traumatic stress disorder (and other fear-memory-overconsolidation disorders, which are misclassified as specific phobias in DSM-IV-TR, e.g. hospital phobia, dentist phobia, dog phobia, bird phobia, and bat phobia).

Finally, contrary to myth, predictions based on brain evolution are eminently testable/falsifiable (Nesse, 1999). Some 30 such predictions are elaborated elsewhere (Bracha, 2006).

Bienvenu, O. J., Onyike, C. U., Stein, M. B., et al (2006) Agoraphobia in adults: incidence and longitudinal relationship with panic. British Journal of Psychiatry, 188, 432-438.

Bracha, H. S. (2006) Human brain evolution and the "Neuroevolutionary Time-depth Principle": implications for the reclassification of fear-circuitry-related traits in DSM-V and for studying resilience to warzonerelated posttraumatic stress disorder. Progress in Neuro-Psychopharmacology and Biological Psychiatry, 30, 827-853.

Kupfer, D. J., First, M. B. \& Regier, D. A. (2002) Research Agenda for DSM-V. Washington, DC: American Psychiatric Association.

Marks, I. M. (1987) Fears, Phobias, and Rituals. New York: Oxford University Press.

Nesse, R. M. (1999) Testing evolutionary hypotheses about mental disorders. In Evolution in Health and Disease (ed. S. C. Stearns), pp. 260-266. Oxford: Oxford University Press.

H. Stefan Bracha National Center for PTSD, Department of Veterans Affairs, Pacific Islands Health Care System, Spark M. Matsunaga Medical Center, and Asia-Pacific Center for Biosecurity, Disaster and Conflict Research, University of Hawaii School of Medicine, Honolulu, USA.

Email: h.bracha@med.va.gov

S. M. Lenze, J. Shelton National Center for PTSD, Department of Veterans Affairs, Pacific Islands Health Care System, Spark M. Matsunaga Medical Center, Honolulu, USA

doi: I0.II92/bjp.I89.5.470a 